\title{
Immunogenicity Specimen Assessments Vendor Name
}

National Cancer Institute

\section{Source}

National Cancer Institute. Immunogenicity Specimen Assessments Vendor Name. NCI

Thesaurus. Code C117566.

The literal identifier of the vendor or laboratory that performs a immunogenicity specimen assessment. 